\title{
EFEITO DA ADIÇÃO DE PARTÍCULAS DE TIO2 NA MICROESTRUTURA E PROPRIEDADES MECÂNICAS DA LIGA AA6005 PROCESSADA POR FSW
}

\author{
Matheus B. Martins*, Rodrigo J. Contieri.
}

\section{Resumo}

O processo de Soldagem por Fricção e Mistura (FSW) se destaca entre os demais processos de união pois é realizado no estado sólido, promovendo a solda através de forças compressivas, rotação e avanço de uma ferramenta não consumível em contato com o material, deformando-o plasticamente. A partir desta técnica é possível obter juntas com menores distorções e maior resistência mecânica, com aplicação nas indústrias automobilística e aeroespacial. Também através do FSW é possível o processamento de compósitos cerâmicos de matriz metálica, visando o aumento de propriedades através do reforço de nanopartículas cerâmicas. O presente trabalho tem como objetivo estudar os efeitos e implicações do FSW no processamento da liga AL6005 na têmpera T6, além de avaliar os resultados da adição de partículas de TiO2 no processamento. Para tanto foram definidos os parâmetros de soldagem para perfis extrudados de espessura 3,4 $\mathrm{mm}$, caracterizando propriedades mecânicas e microestruturais da liga soldada, além de testes de processamento das amostras da liga, com a adição de TiO2 na forma de pó, utilizando uma única ferramenta e carga não variável e variando parâmetros como ângulo de ataque, rotação e avanço e verificando seus efeitos.

\section{Palavras-chave:}

FSW, Alumínio, Rigidez.

\section{Introdução}

$\mathrm{Na}$ indústria, observa-se atualmente a demanda por alta tecnologia em seus processos, a fim de atender padrões cada vez mais elevados de segurança, conforto, desempenho e sustentabilidade. Assim, o desenvolvimento de materiais e ligas leves de alta resistência tem se popularizado, possibilitada graças a novas técnicas de união e processamento, como o FSW, sendo capaz de atingir propriedades mecânicas superiores às convencionais.

Assim, avaliando os efeitos da adição de partículas de dióxido de titânio (TiO2) no aumento do módulo de elasticidade e outras propriedades da liga AL6005-T6 processada por FSW, através da tríade: processo, microestrutura e propriedades, pôde-se investigar as possibilidades de aplicação dessa técnica na indústria.

\section{Resultados e Discussão}

A primeira parte do projeto consistiu em encontrar os parâmetros ótimos de soldagem para a liga, comparando os parâmetros descritos na literatura e realizando testes para diferentes condições, definindo os valores de avanço em 100, 200 e $300 \mathrm{~mm} / \mathrm{min}$ e de rotação em 1000, 1500 e 2000 RPM.

As amostras foram então analisadas através de técnicas como microscopia óptica, MEV, EBSD, ensaios de tração, ensaios de dureza e tomografia de raios $X$. Os valores resultantes dos testes de tração em 3 condições distintas de rotação, comparando com propriedades do material base podem ser vistos na tabela 1 .

Tabela 1. Comparação das diferentes rotações com o material base em termos de LE, LRT e \%AL

\begin{tabular}{|c|c|c|c|c|}
\cline { 2 - 5 } \multicolumn{1}{c|}{} & 1000 RPM & 1500 RPM & 2000 RPM & MB \\
\hline LE (MPa) & 130 & 135 & 130 & 250 \\
\hline LRT (MPa) & 175 & 165 & 140 & 270 \\
\hline$\%$ AL & $7,5 \%$ & $7 \%$ & $3,50 \%$ & $12 \%$ \\
\hline
\end{tabular}

Foi observado assim, que para um avanço de $300 \mathrm{~mm} / \mathrm{min}$, rotações entre 1000 e 1500 RPM obtiveram os melhores resultados, correspondendo a uma eficiência de aproximadamente $60 \%$ em relação ao material base.

Na segunda parte do projeto, utilizando rotações entre 1000 RPM e 1500 RPM e valores de avanço como na primeira parte, foi depositado $\mathrm{TiO} 2$ em forma de pó na superfície do material, que foi em seguida processado por FSW. As amostras foram então avaliadas por microscopia óptica, MEV e ensaios de dureza, obtendo bons resultados para a maior parte das condições, e o surgimento de defeitos como trincas em outras.

\section{Conclusões}

A união e processamento de ligas de alumínio de alta resistência através do FSW apresenta resultados promissores, tanto no que diz respeito à união de chapas e perfis quanto na criação de compósitos superficiais. Foi observado que para garantir que a solda por FSW atinja o resultado desejado é de suma importância observar o aporte térmico do processo e o fluxo do material.

\section{Agradecimentos}

Agradecimentos a todos que possibilitaram a execução do projeto, em especial ao CNPq pelo auxílio financeiro e à UNICAMP por possibilitar 0 acesso à pesquisa. 